\title{
Factors affecting the caregiver burden following traumatic brain injury
}

\author{
(1) Nihal Tezel'1, (1) Ebru Umay ${ }^{1}$, (1) Aytül Çakcı² \\ 1 University of Health Sciences Turkey, Diskapi Yildirim Beyazit Training and Research Hospital, Clinic of Physical Medicine and \\ Rehabilitation, Division of Physical Therapy and Rehabilitation, Ankara, Turkey \\ 2Losante Hospital, Clinic of Physical Therapy and Rehabilitation, Ankara, Turkey
}

\section{Date submitted:}

15.10.2020

Date accepted:

22.01.2021

Online publication date:

15.09.2021

\section{Corresponding Author:}

Nihal Tezel, M.D., University of Health Sciences Turkey, Diskapi Yildirim Beyazit Training and Research Hospital, Clinic of Physical Medicine and Rehabilitation, Division of Physical Therapy and Rehabilitation, Ankara, Turkey nihaltezel@gmail.com

ORCID:

orcid.org/0000-0002-7623-7827

Keywords: Caregiver, caregiver burden, traumatic brain injury

Presented in: Presented as an oral presentation at the $27^{\text {th }}$ Physical Medicine and Rehabilitation Congress on 20 May 2019.

\begin{abstract}
Aims: This study aimed to investigate the factors that had an effect on the burden of the caregivers of moderate to severe traumatic brain injury (TBI) patients.

Methods: Between December 2018 and June 2019, patients with moderate to severe TBI and their caregivers were included in the study. Caregivers were assessed with the Zarit Burden Interview and short form-36 health survey scale, and patients were assessed with the Disability Rating Scale and Functional Independence Measure.
\end{abstract}

Results: The study included 58 patients [age, median (min-max): 45 (21.0-60.0), female 72.4\%]. A negative correlation was found between the caregiver's age, unemployment status and comorbidities with the caregiver burden ( $p=0.007, p=0.073, p=0.168$ respectively). A positive correlation was found between the caregivers who were the members of the family and the caregiver burden $(p=0.001)$. In univariate and multivariate regression analysis, the caregiver's age was found to be independent predictors of the increased burden of care $(p=0.007$, $p=0.016$ ), and being a member of the family was found to be independent predictors of the decreased burden of care $(p=0.001, p=0.048)$.

Conclusions: This study demonstrates the effects of the caregiver's age and relationship with the patient on caregiver burden.

\section{Introduction}

Traumatic brain injury (TBI) is one of the most common causes of death and disability with a wide spectrum of symptoms that range from mild to severe in children and adults (1). TBI can cause many medical, physical, cognitive, behavioral, emotional, social, and economic difficulties. It has a profound effect on the lives of patients and their families (2). Thus, continuity of patient care is of great importance for the patient, the patient's family, and the health care system during both the acute and chronic periods of patients with TBI.

Caregivers play an essential role in the care of patients with TBI. Caregiver burden refers to the physical, psychosocial, and financial hardships that can occur during the course of providing care (3). As the severity of symptoms and disability of the patient increase, the workload, and, consequently, caregiver depression can also increase (4). 
Manskow et al. (1) investigated factors affecting caregiver burden after TBI. They found that communication problems, patient's functional status, and feeling alone were the strongest determinants of caregiver burden. In another study, Qadeer et al. (5) reported that insufficient attention to caregivers resulted in psychological and health complaints. They suggested that caregivers should be educated about medications, management, and health maintenance before discharge.

Factors affecting caregiver burden of patients with chronic diseases like multiple sclerosis, stroke, Parkinson's disease have been investigated in many studies but to our knowledge, this is the first study evaluating the caregiver's burden following TBI in Turkey (6-8). In this study, we aimed to investigate the factors affecting the burden of the caregivers of patients with TBI in a province of Turkey.

\section{Methods}

\section{Study Design}

This cross-sectional single-center study included 58 patients and their caregivers who were hospitalized in a Physical Medicine and Rehabilitation Clinic from December 2018 to June 2019. The study was approved by the University of Health Sciences Turkey, Diskapi Yildirim Beyazit Training and Research Hospital Local Institutional Ethics Committee (approve date: 17.12.2018, approval number: 57/05). Before the study, all patients' caregivers were informed about the study. Written consent was obtained for the study. All procedures were conducted according to the Helsinki Declaration of 2004.

\section{Participants}

The caregiver inclusion criteria were as follows: Age over 18 years and status as the primary caregiver (i.e., living with the patient), being able to read and comprehend the written informed consent form in Turkish.

Exclusion criteria included the inability to give informed consent and refuse to participate in the study.

The patient inclusion criteria were as follows: Age over 18 years, having moderate or severe subacute or chronic period TBI.

The patient exclusion criteria included a previous history of neuropsychiatric disorders due to alcoholism, drug abuse (patient and caregiver), having progressive (multiple sclerosis, amyotrophic lateral sclerosis, etc.) or non-progressive (cerebrovascular disease, cerebral palsy, etc.) neurological disease.

\section{Demographic and Disease Characteristics}

Age, gender, educational status, marital status, occupational status, comorbidity, occupation, number of other persons cared for, and general health $(\mathrm{GH})$ status of each caregiver were recorded. $\mathrm{GH}$ status of the caregivers was assessed with the short form-36 (SF-36) health survey. It has eight domains scored from 0 to 100 , divided across physical and psychological domains: physical functioning, role physical, bodily pain, $\mathrm{GH}$, vitality, social functioning, role emotional, and mental health (MH) (9). SF-36 results can be aggregated into two summary measures, the physical component summary (PCS) and the mental component summary (MCS). The PCS and MCS scores were used in this study. The Turkish language validation of the SF-36 was previously accomplished (10).

Caregiver burden was assessed using the Zarit Burden Interview (ZBI), one of the most commonly used instruments to evaluate the physical, psychological, and social consequences of caring activities. The ZBI was developed by Zarit et al. (11) in 1980. It consists of 22 items rated on a 5-point Likert scale that ranges from 0 (never) to 4 (nearly always) with the sum of scores ranging between 0 and 88 . The ZBI reflects caregiver burden, with higher scores being associated with increased burden. A validity study for ZBI was previously completed (12).

For each patient, the age, sex, educational status, presence of additional injuries, duration of coma, hospitalization, homestay, and total trauma (in days), as well as the presence of tracheostomy and/or gastrostomy, mechanical ventilation, spasticity, and presence of bowel and/or bladder dysfunction, Disability Rating Scale (DRS), and Functional Independence Measure (FIM) scores, were recorded. The DRS was previously developed and tested in patients with moderate and severe TBI, particularly during rehabilitation. It can track an individual from the stage of coma to rehabilitation in the community and classifies recovery according to three categories: impairment, disability, and handicap (13). The lowest score is 0 , which represents no disability. The highest score is 29 , which represents the extreme vegetative state. The DRS total score was used in this study to represent the level of functioning of the patient with TBI.

FIM is widely used and accepted as an assessment of the functional status of patients with neurologic disorders (14). It is composed of 18 items divided into 6 parts. The highest score 126 indicates total independence in functional activities. The Turkish versions of the FIM were validated previously (15). Each item is scored from 1 to 7 (1 point indicates complete dependence, 7 points indicates complete independence).

\section{Statistical Analysis}

Data analyses were made using the Statistical Package for the Social Sciences 22.0 for Windows. The continuous variables were evaluated with the Kolmogorov-Smirnov test as to whether or not they were different from a normal distribution. Descriptive statistics were shown as mean \pm standard deviation and median (minimum-maximum) for continuous variables and frequencies and percentages (\%) for categorical variables. 
Point biserial (categorical) and Spearman's correlation tests were used to establish the relationship between the caregiver burden scale scores and demographic and disease variables. The univariate logistic regression analysis for significant correlations (age, working state as unemployment, presence of comorbidity, and being a member of the informal caregiver) and multivariate regression analysis were performed. The statistical significance level was set at $p<0.05$.

\section{Results}

The median caregiver age was 46.0 years (range: $21.0-$ $60.0)$. Forty-two $(72.4 \%)$ of the caregivers were female, while $16(27.6 \%)$ were male. The median patient age was 30.0 (18.0-64.0) years. Fourteen (24.1\%) patients were female and $44(75.9 \%)$ were male. Twenty-seven $(44.8 \%)$ patients and their caregivers had the same gender. The characteristics of the caregivers and patients are presented in Table 1 and Table 2.

The patients' mean DRS score was $15.4 \pm 7.8$. The median FIM score was 32.0 (range: 18.0-115.0). The median $\mathrm{MH}$ score of the caregivers according to the SF-36 scale was 35.1 (range: 4.5-77.5), and the median physical health score was 46.6 (27.7-95.5). ZBI severity was mild in 9 (15.5\%), mild to moderate in $8(13.8 \%)$, moderate to severe in $28(48.3 \%)$, and severe in 13 patients (22.4\%).

Correlation results between caregivers' caregiver burden scale scores and caregiver and patient characteristics are presented in Table 3 and Table 4, respectively.

We found a significant correlation between caregiver burden and caregiver's age, employment status, relationship with the patient (formal, informal caregiver), and comorbidity $(r=0.306, p=0.019, r=0.280, p=0.033, r=-0.578, p=0.021$ and $r=0.251, p=0.048$, respectively). We found a significant positive correlation between the age of the caregiver and working status of unemployment and comorbidity of the caregiver. Also, we found a significant negative correlation between caregiver burden and informal caregivers.

We did not find a significant correlation between demographics and disease characteristics of the patients and caregiver burden scores $(p>0.05)$.

In univariate and multivariate regression analyses, the caregiver's age was found to be independent predictor of the increased burden of care $(p=0.007, p=0.016)$, and being a member of the family was found to be independent predictor of the decreased burden of care $(p=0.001, p=0.048)$ (Table 5 , Table 6).

\section{Discussion}

Mortality rates related to TBIs have decreased dramatically with advances in intensive care services, but morbidity has increased (5). TBI affects the family and patient both socioeconomically and psychologically because their lives

\begin{tabular}{|c|c|}
\hline & $\begin{array}{l}\mathrm{n}=58 \\
\text { Mean } \pm S D, \text { median (min-max), } \mathrm{n}(\%)\end{array}$ \\
\hline Age (years) & $45(21.0-60.0)$ \\
\hline \multicolumn{2}{|l|}{ Sex } \\
\hline Female & $42(72.4)$ \\
\hline Male & $16(27.6)$ \\
\hline \multicolumn{2}{|l|}{ Educational status } \\
\hline Illiterate & 0 \\
\hline Literate & $4(6.9)$ \\
\hline Primary school & $21(36.2)$ \\
\hline Secondary school & $28(48.3)$ \\
\hline High school & $5(8.6)$ \\
\hline University or higher & 0 \\
\hline \multicolumn{2}{|l|}{ Marital status } \\
\hline Married & $56(96.6)$ \\
\hline Single & $2(3.4)$ \\
\hline Divorced & 0 \\
\hline \multicolumn{2}{|l|}{ Working state } \\
\hline Employment & $30(51.7)$ \\
\hline Unemployment & $28(48.3)$ \\
\hline $\begin{array}{l}\text { Presence of } \\
\text { comorbidity }\end{array}$ & $52(89.7)$ \\
\hline $\begin{array}{l}\text { Number of people } \\
\text { living together }\end{array}$ & $3.00(1.0-5.0)$ \\
\hline \multicolumn{2}{|l|}{ SF-36 } \\
\hline $\mathrm{MH}$ & $35.12(4.5-77.5)$ \\
\hline Physical health & $46.62(27.75-95.50)$ \\
\hline \multicolumn{2}{|l|}{ Domains } \\
\hline Physical functioning & $77.50(0.0-100.0)$ \\
\hline $\mathrm{RP}$ & $40.00(0.0-100.0)$ \\
\hline $\mathrm{BP}$ & $53.00(20.0-100.0)$ \\
\hline $\mathrm{GH}$ & $52.00(40.0-86.0)$ \\
\hline V & $45.00(10.0-87.0)$ \\
\hline SF & $37.00(0.0-100.0)$ \\
\hline RE & $30.0(0.0-100.0)$ \\
\hline $\mathrm{MH}$ & $48.00(0.0-72.0)$ \\
\hline $\begin{array}{l}\text { Zarit Caregiver } \\
\text { Burden Scale }\end{array}$ & $45.00(25.0-83.0)$ \\
\hline \multicolumn{2}{|c|}{$\begin{array}{l}\text { SD: Standard deviation, min-max: Minimum-maximum, SF-36: Short form-36, } \\
\text { RP: Role physical, BP: Bodily pain, GH: General health, V: Vitality, SF: Social } \\
\text { functioning, RE: Role emotional, MH: Mental health }\end{array}$} \\
\hline
\end{tabular}

change markedly. Family caregivers play critical roles in the plan of care for patients with chronic diseases (16). In addition to the care itself, increasing economic problems and the physical and emotional demands of long-term care can result in adverse impacts on caregivers. We examined the effects of the following variables on caregiver burden: the patient's comorbidities, intensive care period, spasticity, presence of a tracheostomy or gastrostomy, speech or swallowing disorder, and bladder or bowel dysfunction.

The current study found that the strongest predictors for a high burden were related to the burden on the caregiver and associated with the caregiver's age and relationship with the 


\begin{tabular}{|c|c|}
\hline Characteristics & $\begin{array}{l}\mathrm{n}=58 \\
\text { Mean } \pm S D, \text { median (min- } \\
\max ), \mathrm{n}(\%)\end{array}$ \\
\hline Age (years) & $30.00(18.0-64.0)$ \\
\hline \multicolumn{2}{|l|}{ Sex } \\
\hline Female & $14(24.1)$ \\
\hline Male & $44(75.9)$ \\
\hline \multicolumn{2}{|l|}{ Educational status } \\
\hline Illiterate & 0 \\
\hline Literate & 0 \\
\hline Primary school & $25(43.1)$ \\
\hline Secondary school & $18(31)$ \\
\hline High school & $10(17.3)$ \\
\hline University or higher & $5(8.6)$ \\
\hline Premorbid comorbidity & $10(17.3)$ \\
\hline Hypertension & $9(90)$ \\
\hline Diabetes mellitus & $3(30)$ \\
\hline Coma time (day) & $4.00(1.0-5.0)$ \\
\hline Time after trauma (day) & $269.72 \pm 31.67$ \\
\hline Hospital stay (day) & $144.58 \pm 14.29$ \\
\hline Homestay (day) & $95.72 \pm 2.37$ \\
\hline Concomitant injury & $42(72.4)$ \\
\hline The presence of tracheostomy & $33(56.9)$ \\
\hline The presence of gastrostomy & $35(60.3)$ \\
\hline $\begin{array}{l}\text { The presence of mechanical } \\
\text { ventilation }\end{array}$ & 0 \\
\hline $\begin{array}{l}\text { The presence of swallowing } \\
\text { disorder }\end{array}$ & $34(58.6)$ \\
\hline $\begin{array}{l}\text { The presence of speech } \\
\text { disorder }\end{array}$ & $44(75.9)$ \\
\hline Bladder dysfunction & $45(77.6)$ \\
\hline Bowel dysfunction & $44(75.9)$ \\
\hline Spasticity & $39(67.2)$ \\
\hline DRS (0-29) & $15.48 \pm 7.87$ \\
\hline \multicolumn{2}{|l|}{ FIM } \\
\hline Motor & $24.00(12.0-80.0)$ \\
\hline Cognitive & $10.50(4.0-35.0)$ \\
\hline Total score & $32.0(18.0-115.0)$ \\
\hline
\end{tabular}

DRS: Disability Rating Scale, FIM: Functional Independent Measurement, SD: Standard deviation, min-max: Minimum-maximum

patient. The caregivers experienced moderate levels of burden, which is consistent with many studies that have investigated the caregiver burden related to patients with TBI (17).

In the current study, it was determined that unemployed caregivers had a higher care burden. Like our study, researchers (18) found that employment reduced the burden on the caregiver. Financial difficulties resulting from their unemployed status could negatively affect these caregivers' burdens. It has been suggested that caregivers have to be provided financial support to prevent an increase in caregiver burden due to low income (19).
Table 3. Correlation results of caregiver characteristics and caregiver burden

\begin{tabular}{|c|c|c|}
\hline & $\mathbf{r}$ & $\mathbf{p}$ \\
\hline Age (years) & $0.306^{\circ}$ & 0.019 \\
\hline Sex & $-0.189^{*}$ & 0.155 \\
\hline Educational status & $0.194^{*}$ & 0.145 \\
\hline Marital status & $0.237^{*}$ & 0.073 \\
\hline $\begin{array}{l}\text { Working state } \\
\text { (unemployment) }\end{array}$ & $0.280^{*}$ & 0.033 \\
\hline $\begin{array}{l}\text { Relationship with } \\
\text { patient (family } \\
\text { member) }\end{array}$ & $-0.578^{*}$ & 0.021 \\
\hline Comorbidity & $0.251^{*}$ & 0.048 \\
\hline $\begin{array}{l}\text { Number of people } \\
\text { living together }\end{array}$ & $0.115^{\circ}$ & 0.388 \\
\hline \multicolumn{3}{|l|}{ SF-36 } \\
\hline $\mathrm{MH}$ & $0.160^{\circ}$ & 0.249 \\
\hline Physical health & $-0.211^{\circ}$ & 0.127 \\
\hline \multicolumn{3}{|l|}{ Domains } \\
\hline Physical functioning & -0.181 & 0.196 \\
\hline $\mathrm{RP}$ & -0.134 & 0.338 \\
\hline Pain & -0.258 & 0.060 \\
\hline $\mathrm{GH}$ & 0.037 & 0.491 \\
\hline V & -0.024 & 0.865 \\
\hline SF & -0.201 & 0.150 \\
\hline $\mathrm{RE}$ & 0.029 & 0.834 \\
\hline $\mathrm{MH}$ & 0.201 & 0.149 \\
\hline
\end{tabular}

In the current study, the factor related to the burden was the age of the caregiver. It was observed that the older age of the caregivers increased the caregiver burden. Similar to the current study, Nabors et al. (20) found that the burden of care was higher for older caregivers than for younger caregivers. They explained this with the fact that younger caregivers had fewer needs. Davis et al. (21) suggested that caregivers' preinjury medical and psychiatric histories were both risk factors for caregiver distress. They indicated caregivers who were at risk of developing distress and caregiver burden should be evaluated to prevent distress in the post-acute period.

A substantial part of the care for patients may require longterm and be provided by informal caregivers such as spouses or parents (22). In our study, another factor related to burden was the caregivers' relationship with the patient. We found being family members reduced the caregiver burden. Similarly, Marks et al. (23) reported that caregivers could acquire satisfaction from helping their family members.

In the current study, gender, educational status, marital status, the severity of the patient's injury, and the patient's comorbidities were all found to have no significant impact on caregiver burden. Our findings could be relevant to the disease 


\begin{tabular}{|c|c|c|}
\hline Characteristics & $\mathbf{r}$ & p \\
\hline Age (years) & $-0.003^{\circ}$ & 0.983 \\
\hline Sex & $-0.145^{*}$ & 0.228 \\
\hline Educational status & $-0.064^{*}$ & 0.712 \\
\hline \multicolumn{3}{|l|}{ Premorbid comorbidity } \\
\hline Hypertension & $0.022^{*}$ & 0.168 \\
\hline Diabetes mellitus & $0.138^{*}$ & 0.255 \\
\hline Coma time (day) & $0.014^{\circ}$ & 0.927 \\
\hline Time after trauma (day) & $0.242^{\circ}$ & 0.078 \\
\hline Hospital stay (day) & $-0.041^{\circ}$ & 0.777 \\
\hline Homestay (day) & $0.294^{\circ}$ & 0.038 \\
\hline Concomitant injury & $0.115^{*}$ & 0.409 \\
\hline $\begin{array}{l}\text { The presence of } \\
\text { tracheostomy }\end{array}$ & $0.035^{*}$ & 0.810 \\
\hline $\begin{array}{l}\text { The presence of } \\
\text { gastrostomy }\end{array}$ & $0.063^{*}$ & 0.359 \\
\hline $\begin{array}{l}\text { The presence of } \\
\text { mechanical ventilation }\end{array}$ & $0.128^{*}$ & 0.058 \\
\hline $\begin{array}{l}\text { The presence of } \\
\text { swallowing disorder }\end{array}$ & $-0.043^{*}$ & 0.779 \\
\hline $\begin{array}{l}\text { The presence of speech } \\
\text { disorder }\end{array}$ & $0.120^{*}$ & 0.478 \\
\hline Bladder dysfunction & $0.031^{*}$ & 0.818 \\
\hline Bowel dysfunction & $0.103^{*}$ & 0.442 \\
\hline Spasticity & $-0.210^{*}$ & 0.167 \\
\hline DRS (0-29) & $0.019^{\circ}$ & 0.890 \\
\hline \multicolumn{3}{|l|}{ FIM } \\
\hline Motor & $-0.049^{\circ}$ & 0.713 \\
\hline Cognitive & $-0.037^{\circ}$ & 0.795 \\
\hline Total score & $-0.047^{\circ}$ & 0.736 \\
\hline \multicolumn{3}{|c|}{$\begin{array}{l}\text { DRS: Disability Rating Scale, FIM: Functional Independent Measurement, } \\
\text { *: Point biserial correlation test, }{ }^{\circ} \text { : Spearman's correlation test, } r \text { : Correlation } \\
\text { coefficient }\end{array}$} \\
\hline
\end{tabular}

\begin{tabular}{|c|c|c|c|c|}
\hline & B & SE & $\begin{array}{l}95 \% \mathrm{Cl} \text { (lower- } \\
\text { upper) for B }\end{array}$ & p \\
\hline Age & 0.552 & 0.208 & $0.136-0.968$ & 0.007 \\
\hline $\begin{array}{l}\text { Having a } \\
\text { comorbidity }\end{array}$ & 1.217 & 0.712 & $0.933-5.412$ & 0.168 \\
\hline Unemployment & 4.885 & 2.675 & $0.467-10.237$ & 0.073 \\
\hline $\begin{array}{l}\text { Being an informal } \\
\text { caregiver }\end{array}$ & 1.381 & 0.380 & $0.618-2.143$ & 0.001 \\
\hline
\end{tabular}

features of the patients who participated in the study. A review that focused on factors affecting the caregiver burden of TBI patients reported more caregiver burden for spouses and

\begin{tabular}{|c|c|c|c|c|}
\hline & B & SE & $\begin{array}{l}95 \% \mathrm{Cl} \\
\text { (lower- } \\
\text { upper) for B }\end{array}$ & p \\
\hline Age & 0.848 & 0.327 & $0.175-1.521$ & 0.016 \\
\hline $\begin{array}{l}\text { Being an informal } \\
\text { caregiver }\end{array}$ & 6.517 & 3.142 & $0.034-12.996$ & 0.048 \\
\hline
\end{tabular}

women than for parents and men. They reported that $48.8 \%$ of TBI patients reported divorce or separation from their spouse, and $6.10 \%$ of still married individuals reported having problems in their marriage. Also, they have reported that providing social support has a positive effect on the caregiver burden. Similar to our study, in this review, the severity of the injury was found to have no significant impact on the caregiver burden (5).

Patients and caregivers need long-term professional followup to alleviate the caregiver burden $(1,24)$. A study showed that telephone-based problem-solving interventions improved the well-being of $\mathrm{TBI}$ caregivers. They found that the caregivers who received telephone-based problem-solving interventions felt better and were able to care for themselves and reported using more active coping skills (25). Also clinicians should focus on providing caregiver education including managing stress, coping, and problem-solving strategies. It is important to take care of the needs of caregivers and to ensure them with sufficient social, economic, physical, and psychological support (26).

The strength of the current study is that we used validated assessment tools. Also, caregivers were evaluated not only with the $\mathrm{ZBI}$ but also with the health survey scale. Limitations of our study are that it did not assess the level of social support provided to caregivers and it included a small sample size of participants from a single center. Another limitation is our lack of information about the premorbid properties that could affect the caregiver's ability to cope with the situation. In future studies, a larger sample from different regions of our country will better identify the factors affecting caregiver burden.

\section{Conclusion}

Caregivers play a very important role in the subacute-chronic period rehabilitation after moderate to severe TBI. This study highlights the factors that affect the burden by primary caregivers of adults with moderate to severe TBI. This study provides important information about the burden of care, particularly by demonstrating that a caregiver's age and relationship to the patient contribute to the level of caregiver burden.

Understanding the relevant factors that affect caregiver burden may help identify and take early interventions for caregivers who are at a risk for high burden. Since post-TBI care 
involves a very long process, meeting the needs of caregivers and supporting them both psychologically and financially are important to reduce the caregiver's burden and to improve the quality of life of the patient.

\section{Ethics}

Ethics Committee Approval: The study was approved by the University of Health Sciences Turkey, Diskapi Yildirim Beyazit Training and Research Hospital Local Institutional Ethics Committee (approval date: 17.12.2018, approval number: 57/05).

Informed Consent: All patients' caregivers were informed about the study

Peer-review: Externally peer-reviewed.

\section{Authorship Contributions}

Concept: N.T., Design: N.T., E.U., A.Ç. Data Collection or Processing: N.T., E.U., Analysis or Interpretation: E.U., Literature Search: N.T., E.U., A.Ç. Writing: N.T.

Conflict of Interest: No conflict of interest was declared by the authors.

Financial Disclosure: The authors declared that this study received no financial support.

\section{References}

1. Manskow US, Sigurdardottir S, Røe C, et al. Factors Affecting Caregiver Burden 1 Year After Severe Traumatic Brain Injury: A Prospective Nationwide Multicenter Study. J Head Trauma Rehabil. 2015;30:411-423.

2. Stocchetti N, Carbonara M, Citerio G, et al. Severe traumatic brain injury: targeted management in the intensive care unit. Lancet Neurol. 2017;16:452-464.

3. Oyegbile YO, Brysiewicz P. Exploring caregiver burden experienced by family caregivers of a ptients with Endstage Renal Disease in Nigeria. International Journal of Africa Nursing Sciences. 2017;7:136-143.

4. Blake H. Caregiver stress in traumatic brain injury. Int $\mathrm{J}$ Ther Rehabil. 2013;15:263-271.

5. Qadeer A, Khalid U, Amin M, Murtaza S, Khaliq MF, Shoaib M. Caregiver's Burden of the Patients With Traumatic Brain Injury. Cureus. 2017;9:e1590.

6. Akkuş Y. Multiple sclerosis patient caregivers: the relationship between their psychological and social needs and burden levels. Disabil Rehabil. 2011;33:326-333.

7. Tosun ZK, Temel M. Burden of Caregiving for Stroke Patients and The Role of Social Support Among Family Members: An Assessment Through Home Visits. International Journal of Caring Sciences. 2017;10:1696-1704.

8. Ozdilek B, Gunal DI. Motor and non-motor symptoms in Turkish patients with Parkinson's disease affecting family caregiver burden and quality of life. J Neuropsychiatry Clin Neurosci. 2012;24:478-483.
9. Ware JE Jr, Sherbourne CD. The MOS 36-item short-form health survey (SF-36). I. Conceptual framework and item selection. Med Care. 1992;30:473-483.

10. Koçyiğit H, Aydemir Ö, Ölmez N, et al. Kısa Form-36 (SF36)'nın Türkçe versiyonunun güvenilirliği ve geçerliliği. İlaç ve Tedavi Dergisi. 1996;12:102-106.

11. Zarit SH, Reever KE, Bach-Peterson J. Relatives of the impaired elderly: correlates of feelings of burden. Gerontologist. 1980;20:649-655.

12. Inci F, Erdem M. Validity and Reliability of the Burden Interview and Its Adaptation to Turkish. Atatürk Üniversitesi Hemşirelik Yüksekokulu Dergisi. 2008;11:85-95.

13. Rappaport M. The Disability Rating and Coma/Near-Coma scales in evaluating severe head injury. Neuropsychol Rehabil. 2005;15:442-453.

14. Keith RA, Granger CV, Hamilton BB, Sherwin FS. The functional independence measure: a new tool for rehabilitation. Adv Clin Rehabil. 1987;1:6-18.

15. Küçükdeveci A, Yavuzer G, Elhan A, et al. Adaptation of the Functional Independence Measure for use in Turkey. Clinical Rehabilitation. 2001;15:311-319.

16. Goldberg A, Rickler KS. The role of family caregivers for people with chronic illness. Med Health R I. 2011;94:41-42.

17. Saban KL, Griffin JM, Urban A, Janusek MA, Pape TL, Collins E. Perceived health, caregiver burden, and quality of life in women partners providing care to Veterans with traumatic brain injury. J Rehabil Res Dev. 2016;53:681692.

18. Irfan B, Irfan O, Ansari A, Qidwai W, Nanji K. Impact of Caregiving on Various Aspects of the Lives of Caregivers. Cureus. 2017;9:e1213.

19. Scazufca M, Kuipers E. Stability of expressed emotion in relatives of those with schizophrenia and its relationship with burden of care and perception of patients' social functioning. Psychol Med. 1998;28:453-461.

20. Nabors N, Seacat J, Rosenthal M. Predictors of caregiver burden following traumatic brain injury. Brain Inj. 2002;16:1039-1050.

21. Davis LC, Sander AM, Struchen MA, Sherer M, NakaseRichardson R, Malec JF. Medical and psychosocial predictors of caregiver distress and perceived burden following traumatic brain injury. J Head Trauma Rehabil. 2009;24:145-154.

22. Sandberg M, Jakobsson U, Midlöv P, Kristensson J. Costutility analysis of case management for frail older people: effects of a randomised controlled trial. Health Econ Rev. 2015;5:51.

23. Marks NF, Lambert JD, Choi H. Transitions to caregiving, gender, and psychological well-being: A prospective U.S. national study. Journal of Marriage and Family. 2002;64:657-667. 
24. Moy Martin EM, Langbein J. A Needs Review of Caregivers for Adults With Traumatic Brain Injury. Fed Pract. 2017;34:42-49.

25. Powell JM, Fraser R, Brockway JA, Temkin N, Bell KR. A Telehealth Approach to Caregiver Self-Management
Following Traumatic Brain Injury: A Randomized Controlled Trial. J Head Trauma Rehabil. 2016;31:180-190.

26. Mbakile-Mahlanza L, Manderson L, Downing M, Ponsford J. Family caregiving of individuals with traumatic brain injury in Botswana. Disabil Rehabil. 2017;39:559-567. 